Revista Brasil. Bot., V.32, n.3, p.427-440, jul.-set. 2009

\title{
Poliporóides (Basidiomycota) em fragmentos de mata no perímetro urbano de São José do Rio Preto, São Paulo, Brasil
}

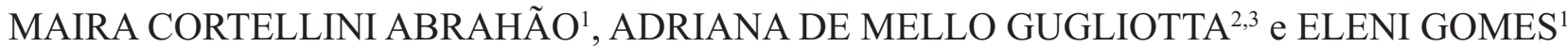

(recebido: 24 de abril de 2008; aceito: 01 de abril de 2009)

\begin{abstract}
Polyporoid (Basidiomycota) in forest fragments of São José do Rio Preto urban perimeter, São Paulo, Brazil). A survey of polyporoid fungi from forest fragments of São José do Rio Preto urban perimeter (2049'12" S, 49²2'44" W), São Paulo state, Brazil was carried out. Eighteen taxa belonging to 11 genera of Agaricales (Schizophyllaceae), Hymenochaetales (Hymenochaetaceae) and Polyporales (Ganodermataceae, Gloeophyllaceae, Meruliaceae and Polyporaceae) were identified: Coriolopsis floccosa (Jungh.) Ryvarden, C. polyzona (Pers.) Ryvarden, Datronia caperata (Berk.) Ryvarden, D. mollis (Somf.: Fr.) Donk., Ganoderma australe (Fr.) Pat., Gloeophyllum striatum (Sw.) Murrill, Gloeoporus thelephoroides (Hook.) G. Cunn., Hexagonia hirta (P. Beauv.) Fr., H. hydnoides (Sw.) M. Fidalgo, H. papyracea Berk., Polyporus tenuiculus (P. Beauv.) Fr., Phellinus callimorphus (Lév.) Ryvarden, P. gilvus (Schwein.) Pat., P. umbrinellus (Bres.) Herrera \& Bondartseva, Pycnoporus sanguineus (L.) Murrill, Schizophyllum commune Fr., S. umbrinum Berk. and Trametes modesta (Kunze:Fr.) Ryvarden. Datronia mollis is a new record for São Paulo state. Identification key, descriptions and comments of the taxa studied are provided.
\end{abstract}

Key words - Agaricales, Hymenochaetales, Polyporales, taxonomy

RESUMO - (Poliporóides (Basidiomycota) em fragmentos de mata no perímetro urbano de São José do Rio Preto, São Paulo, Brasil). Foi realizado levantamento das espécies de fungos poliporóides que ocorrem no perímetro urbano do município de São José do Rio Preto (2049'12” S, 49²2’44” W), Estado de São Paulo, Brasil. Foram identificadas 18 espécies pertencentes a 11 gêneros de Agaricales (Schizophyllaceae), Hymenochaetales (Hymenochaetaceae) e Polyporales (Ganodermataceae, Gloeophyllaceae, Meruliaceae e Polyporaceae): Coriolopsis floccosa (Jungh.) Ryvarden, C. polyzona (Pers.) Ryvarden, Datronia caperata (Berk.) Ryvarden, D. mollis (Somf.:Fr.) Donk., Ganoderma australe (Fr.) Pat., Gloeophyllum striatum (Sw.) Murrill, Gloeoporus thelephoroides (Hook.) G. Cunn., Hexagonia hirta (P. Beauv.) Fr., H. hydnoides (Sw.) M. Fidalgo, H. papyracea Berk., Polyporus tenuiculus (P. Beauv.) Fr., Phellinus callimorphus (Lév.) Ryvarden, P. gilvus (Schwein.) Pat., P. umbrinellus (Bres.) Herrera \& Bondartseva, Pycnoporus sanguineus (L.) Murrill, Schizophyllum commune Fr., S. umbrinum Berk. e Trametes modesta (Kunze:Fr.) Ryvarden. Datronia mollis é nova citação para o Estado de São Paulo. São apresentados chave de identificação, descrições e comentários para cada táxon estudado.

Palavras-chave - Agaricales, Hymenochaetales, Polyporales, taxonomia

\section{Introdução}

Basidiomicetos poliporóides apresentam ampla distribuição nos biomas terrestres possuindo papel fundamental na degradação da celulose e lignina de materiais vegetais lenhosos e, portanto, na ciclagem de nutrientes e na manutenção dos ecossistemas (Rayner 1995).

A maioria das espécies é saprotrófica, mas algumas são parasitas. Enquanto algumas são extremamente agressivas, estabelecendo-se na árvore ainda viva ou recém morta, outras são colonizadoras secundárias e se estabelecem apenas após a colonização do substrato por outras espécies (Ryvarden 1991).

\footnotetext{
1. Universidade Estadual Paulista, Instituto de Biociências, Letras e Ciências Exatas, Departamento de Biologia, R. Cristóvão Colombo 2.265, Jd. Nazareth, 15054-000 São José do Rio Preto, SP, Brasil.

2. Instituto de Botânica, Seção de Micologia e Liquenologia, Caixa Postal 3005, 01061-970 São Paulo, SP, Brasil.

3. Autor para correspondência: agugliottaibot@yahoo.com.br
}

A taxonomia do grupo vem sofrendo modificações na medida em que são incorporados resultados de estudos com biologia molecular. Estes estudos sugerem que o himênio poróide evoluiu independentemente várias vezes entre os Basidiomycota (Hibbett \& Thorn 2001) e ainda hoje a posição taxonômica de algumas espécies de poliporóides continua incerta devido à grande convergência dos caracteres morfológicos e falta de estudos moleculares. Espécies poliporóides estão presentes em diversas ordens da subclasse Agaricomycetidae, sobretudo em Agaricales, Hymenochaetales, Polyporales, Russulales e Thellephorales (Kirk et al. 2001).

A diversidade de poliporóides da região noroeste do Estado de São Paulo, na qual o município de São José do Rio Preto está localizado, é praticamente desconhecida, havendo apenas um trabalho de grande abrangência (Xavier-Santos 2003). No entanto, este trabalho não possui enfoque taxonômico, uma vez que o objetivo foi estudar o sistema enzimático de fungos decompositores de madeira, recém-coletados na Estação Ecológica do 
Noroeste Paulista, localizada entre os municípios de São José do Rio Preto e Mirassol, apresentando apenas a listagem dos táxons encontrados.

O presente trabalho tem como objetivo contribuir para o conhecimento da diversidade de basidiomicetos poliporóides em fragmentos de mata no perímetro urbano de São José do Rio Preto e da região noroeste do Estado de São Paulo.

\section{Material e métodos}

O município de São José do Rio Preto está localizado na região noroeste do Estado de São Paulo (2049'12" S e $49^{\circ} 22^{\prime} 44^{\prime}$ W), que apresenta vegetação caracterizada como floresta estacional semidecidual e clima tropical de altitude, com temperatura média anual em torno de $25^{\circ} \mathrm{C}$ e precipitação média do mês mais seco inferior a $60 \mathrm{~mm}$.

Foram realizadas coletas mensais no período de março/2005 a junho/2006, abrangendo quatro áreas de matas resquiciais de tal modo distribuídas: cinco coletas na mata do Bosque Municipal, três coletas na mata situada na Rodovia Transbrasiliana (BR153) próxima à entrada do distrito de Talhados, duas coletas no Seringal da Fazenda Genética Triálogo e duas na Mata dos Macacos, no caminho para o município de Bady Bassit.

A coleta, preservação e herborização do material seguiram as recomendações técnicas de Fidalgo \& Bononi (1984). Para desidratação, os fungos foram mantidos em estufa em temperaturas entre $50{ }^{\circ} \mathrm{C}$ e $60^{\circ} \mathrm{C}$.

A identificação das espécies foi baseada em caracteres macro e micromorfológicos do basidioma (Teixeira 1995, Ryvarden 1991) e na evidência de reações dextrinóides e amilóides, testadas em reagente de Melzer (Teixeira 1995). As microestruturas foram analisadas segundo recomendações de Teixeira (1995).
Os cortes foram feitos à mão livre, com uso de lâmina de metal. $\mathrm{O}$ fragmento do fungo a ser examinado foi imerso em álcool $70 \%$, por 1 a 2 minutos para re-hidratação e montado entre lâmina e lamínula em gota de solução de $\mathrm{KOH}$ 3-5\%. Estruturas muito hialinas e de difícil observação, foram evidenciadas ao combinar uma gota de $\mathrm{KOH} \mathrm{3-5 \%} \mathrm{com} \mathrm{uma}$ gota de solução aquosa de floxina $1 \%$. Todas as medidas (10 repetições) foram efetuadas em solução de $\mathrm{KOH}$.

Para identificação das espécies foi utilizada bibliografia pertinente e comparação com outros espécimes depositados no Herbário Maria Eneyda P. K. Fidalgo (SP).

Todo material coletado foi depositado no Herbário SP. A terminologia seguiu Fidalgo e Fidalgo (1967). Nomenclatura e classificação seguiram Kirk et al. (2001) e consultadas nas bases de dados do Fungal Biodiversity Centre (CBS 2008) e do Index Fungorum (CABI Bioscience et al. 2008).

\section{Resultados e discussão}

Um total de 80 espécimes foi coletado no perímetro urbano de São José do Rio Preto. Foram identificados 18 táxons distribuídos em 11 gêneros, seis famílias e três ordens: Agaricales (Schizophyllaceae), Hymenochaetales (Hymenochaetaceae) e Polyporales (Ganodermataceae, Gloeophyllaceae, Meruliaceae e Polyporaceae).

Apesar de ter realizado um levantamento abrangendo todos os grupos de decompositores de madeira, Xavier-Santos (2003) encontrou na região 32 táxons poliporóides distribuídos nas famílias Ganodermataceae, Hymenochaetaceae, Meruliaceae, Polyporaceae e Schizophyllaceae; semelhante aos dados do presente trabalho, a família Polyporaceae foi a melhor representada.

Chave de identificação para as espécies poliporóides que ocorrem em fragmentos de mata no perímetro urbano de São José do Rio Preto

1. Basidioma cupulóide, superfície himenial aparentemente lamelar, formada por cânulas radiais enroladas

2. Basidiomas pequenos, 0,2-1 × 0,2-1,8 cm, superfície pilear castanha, basidiósporos elipsóides a apiculados obliquamente Schizophyllum umbrinum

2. Basidiomas 0,5-4 × 0,4-1,3 cm, superfície pilear acinzentada, basidiósporos cilíndricos a alantóides Schizophyllum commune

1. Basidioma não cupulóide, superfície himenial lamelar ou poróide

3. Superfície himenial lamelar Gloeophyllum striatum

3. Superfície himenial poróide

4. Basidioma vermelho-alaranjado, esbranquiçado quando velho Pycnoporus sanguineus

4. Basidioma branco, castanho-claro a castanho-escuro

5. Hifa generativa com septo simples

6. Superfície pilear branca, basidiósporos alantóides, 2,5-5 × 1,25 $\mu \mathrm{m}$ 
6. Superfície pilear castanho-ferrugínea, basidiósporos oblongo-elipsóides a subglobosos

7. Basidioma ressupinado, setas himeniais ausentes Phellinus umbrinellus

7. Basidioma pileado séssil, setas himenias presentes

8. Poros muito pequenos, $8-11$ poros por $\mathrm{mm}$, setas ventricosas, $20-30 \times 5-8,75 \mu \mathrm{m}$ Phellinus callimorphus

8. Poros maiores, $6-8$ poros por $\mathrm{mm}$, setas subuladas a ventricosas, $20-45 \times 6,25-10 \mu \mathrm{m}$ Phellinus gilvus

5. Hifa generativa com ansa

9. Basidiósporos castanho-dourados, de parede dupla, com a parede externa lisa e a parede interna ornamentada Ganoderma australe

9. Basidiósporos hialinos, com parede simples e lisa

10. Basidioma estipitado

Polyporus tenuiculus

10. Basidioma séssil, pileado a ressupinado

11. Poros pequenos, 6-10 poros por $\mathrm{mm}$

Trametes modesta

11. Poros grandes, até 5 poros por $\mathrm{mm}$

12. Sistema hifálico dimítico

13. Basidioma efuso-reflexo a ressupinado, poros circulares a angulares, freqüentemente lacerados, 1-2 poros por mm Datronia mollis

13. Basidioma pileado séssil a efuso-reflexo, poros circulares, 3-4 poros por $\mathrm{mm}$ Datronia caperata

12. Sistema hifálico trimítico

14. Superfície pilear com pêlos bem desenvolvidos, fibrilosa a fimbriada

15. Superfície pilear fimbriada, poros regulares, circulares, 3-5 poros por $\mathrm{mm}$ Hexagonia hydnoides

15. Superfície pilear fibrilosa, poros angulares, isodiamétricos a alongados, extremamente variáveis em tamanho, 8-16 poros por $\mathrm{cm}$ Hexagonia hirta

14. Superfície pilear velutina a glabra

16. Contexto homogêneo, castanho-escuro, superfície pilear com zonas purpúreas e castanhas, claras e escuras ....... Hexagonia papyracea

16. Contexto dúplex, castanho-claro, superfície pilear bege a castanho-clara

17. Basidioma efuso-reflexo a ressupinado, poros angulares a circulares, tornando-se lacerados e denteados em espécimes velhos, 2-5 poros por mm Coriolopsis floccosa

17. Basidioma pileado séssil, às vezes reflexo com uma base efusa de onde crescem os píleos, poros angulares a circulares, 2-3 poros por $\mathrm{mm}$ Coriolopsis polyzona

\section{AGARICALES}

\section{SCHIZOPHYLLACEAE}

Schizophyllum commune Fr., Observ. mycol. (Havniae) 1: 103.1815.

Basidioma anual, pileado séssil, imbricado, lateralmente atado. Píleo flabeliforme, coriáceo, 0,5-4 $\times 0,4-1,3 \mathrm{~cm}$, até $0,1 \mathrm{~cm}$ de espessura. Superfície pilear vilosa, radialmente estriada, concentricamente zonada, acinzentada; margem vilosa, lobada, freqüentemente incisa e involuta, concolor à superfície pilear. Superfície himenial aparentemente lamelar, formada por cânulas radiais enroladas, cinza-acastanhada. Contexto homogêneo, concolor à superfície himenial. Reação em $\mathrm{KOH}$ negativa. Sistema hifálico monomítico; hifas generativas não amilóides e não dextrinóides, com ansas, hialinas, parede fina a espessa, 2,5-6,25 $\mu \mathrm{m}$ diâm. 
Basídios não observados. Basidiósporos cilíndricos a alantóides, hialinos, não amilóides e não dextrinóides, parede fina e lisa, 2,5-6,25 × 1,25-2,5 $\mu \mathrm{m}$.

Material examinado: BRASIL. São PAULo: São José do Rio Preto, Bosque Municipal, 26-IX-2005, M.C. Abrahão 7 (SP); Mata dos Macacos, 13-XII-2005, M.C. Abrahão 56 (SP); Fazenda Genética Triálogo, mata do seringal, 25-III-2006, M.C. Abrahão 75, 81, 92 (SP).

Ilustrações em Linder (1933) e Pegler (1983).

Espécie de distribuição cosmopolita (Cooke 1961). No Brasil, citada para Amapá, Bahia, Pará, Paraná, Pernambuco, Rio Grande do Sul, Rondônia, Roraima, Santa Catarina e São Paulo (Rick 1963, Bononi et al. 1981, Capelari \& Maziero 1988, Jesus 1993, Jesus 1996, Maia et al. 2002, Sotão et al. 2002, 2003, Gibertoni \& Cavalcanti 2003, Góes-Neto et al. 2003, Groposo \& Loguercio-Leite 2005, Xavier-Santos 2003, Meijer 2006).

Espécie muito comum de ampla distribuição mundial, podendo ser parasita ou saprófita em diversos substratos, mais raramente em coníferas (Pegler 1983). Schizophyllum commune pode ser reconhecido pelo basidioma acinzentado, viloso e aparentemente lamelado.

Schizophyllum umbrinum Berk., Hooker's J. Bot. Kew Gard. Misc. 3: 15. 1851.

Basidioma pequeno, solitário ou agregado, subestipitado a lateralmente estipitado. Píleo suborbicular a flabeliforme, 0,2-1 × 0,2-1,8 cm, até $0,1 \mathrm{~cm}$ de espessura. Estipe estrigoso e com pêlos brancos. Superfície pilear castanho-amarelada a castanho-escura; margem vilosa, lobada, freqüentemente incisa e involuta, concolor à superfície pilear. Superfície himenial aparentemente lamelar, formada por cânulas radiais enroladas, castanha. Contexto homogêneo, castanho-claro. Reação em KOH negativa. Sistema hifálico monomítico; hifas generativas não amilóides e não dextrinóides, com ansas, hialinas, parede fina a espessa, 1,25-3,75 $\mu \mathrm{m}$ diâm. Basídios não observados. Basidiósporos elipsóides e apiculados obliquamente, hialinos, não amilóides e não dextrinóides, parede fina e lisa, 2,5-3,75 (-5) × 1,25-2 (-2,5) $\mu \mathrm{m}$.

Material examinado: BRASIL. São PAULO: São José do Rio Preto, Bosque Municipal, 26-IX-2005, M.C. Abrahão 15, 16 (SP); Fazenda Genética Triálogo, mata do seringal, 25-III-2006, M.C. Abrahão 89, 91 (SP).

Ilustrações em Linder (1933).

Espécie de distribuição neotropical (Cooke 1961). No Brasil citado para os Estados do Pará e São Paulo (Sotão et al. 2003, Xavier-Santos 2003).
Schizophyllum umbrinum é reconhecido pelo basidioma pequeno de coloração castanha. Schizophyllum brasiliense W. B. Cooke, descrito para o Estado do Mato Grosso, também possui basidioma pequeno castanhoescuro, mas pode ser diferenciado pelos basidiósporos cilíndricos, 9-11 × 2-2,5 $\mu \mathrm{m}$, bem maiores que em $S$. umbrinum (Cooke 1961).

As características do material examinado conferem com as dos exemplares coletados no noroeste paulista e cuja identificação foi confirmada por estudo de biologia molecular (Xavier-Santos 2003).

\section{HYMENOCHAETALES}

\section{HYMENOCHAETACEAE}

Phellinus callimorphus (Lév.) Ryvarden, in Ryvarden \& Johansen, Prelim. Polyp. Fl. E. Afr. (Oslo): 145. 1980. $\equiv$ Polyporus callimorphus Lév. Annls. Sci. Nat. Bot., sér. 3. 5: 133. 1846.

Basidioma anual, pileado séssil, solitário, coriáceo a lenhoso. Píleo dimidiado a conchado ou mais lateralmente conato, $1,5-3,8 \times 0,8-1,6 \mathrm{~cm}, 0,4-0,8 \mathrm{~cm}$ de espessura. Superfície pilear finamente velutina a glabra, concentricamente zonada e sulcada, castanhoferrugínea; margem glabra, achatada, inteira, concolor à superfície pilear. Superfície himenial poróide, castanhoferrugínea, poros muito pequenos, circulares, 8-11 poros por $\mathrm{mm}$; tubos concolores à superfície himenial, 1-3 mm de profundidade. Contexto homogêneo, castanhoferrugíneo, até $6 \mathrm{~mm}$ de espessura. Reação em $\mathrm{KOH}$ positiva. Sistema hifálico dimítico; hifas não amilóides e não dextrinóides; hifas generativas com septo simples, hialinas a amarelas, parede fina a ligeiramente espessa, 1,5-2,5 $\mu \mathrm{m}$ diâm.; hifas esqueléticas castanhas, com parede espessa, 2,5-5 $\mu \mathrm{m}$ diâm. Setas presentes, ventricosas, castanho-escuras em $\mathrm{KOH}$, parede espessa, 20-30 × 5-8,75 $\mu \mathrm{m}$. Basídios e basidiósporos não observados.

Material examinado: BRASIL. São Paulo: São José do Rio Preto, Bosque Municipal, 21-V-2005, M.C. Abrahão 6 (SP).

Ilustrações em Soares \& Gugliotta (1998) e Ryvarden \& Johansen (1980).

Segundo Ryvarden \& Johansen (1980), a espécie ocorre na África, e Phellinus roseo-cinereo (Murrill) D. A. Reid, considerado sinônimo, tem ampla distribuição na América Central. No Brasil é citada para os Estados do Paraná, Santa Catarina e São Paulo (LoguercioLeite \& Wright 1991, Soares \& Gugliotta 1998, Meijer 2006). 
A ausência de basidiósporos dificultou a identificação do espécime, porém as características macroscópicas (como dimensão do basidioma, coloração e tamanho dos poros) e microscópicas (como dimensão das hifas, presença e formato de setas himeniais) e reação positiva em $\mathrm{KOH}$ estão de acordo com a descrição de Ryvarden \& Johansen (1980) e de Soares \& Gugliotta (1998). Segundo Ryvarden \& Johansen (1980), esta espécie apresenta basidiósporos oblongo-elipsóides a subcilíndricos, hialinos, de parede fina, 3,5-4,5 $\times$ $2-3 \mu \mathrm{m}$.

Phellinus gilvus (Schwein.) Pat., Essai Tax. Hyménomyc. 82. 1900. $\equiv$ Boletus gilvus Schwein., Schr. naturf. Ges. Leipzig 1: 96. 1822.

Basidioma anual a perene, pileado séssil, solitário. Píleo dimidiado, lenhoso, 1,1-7,6 × 0,8-2,0 cm, 0,3$0,8 \mathrm{~cm}$ de espessura. Superfície pilear finamente velutina a glabra, concentricamente zonada e sulcada, castanhoescura; margem finamente velutina, aguda, inteira a lobada, zona inferior estéril. Superfície himenial poróide, poros circulares, $6-8$ poros por $\mathrm{mm}$, castanhoferrugínea; tubos concolores à superfície himenial. Contexto homogêneo, castanho-ferrugíneo. Reação em $\mathrm{KOH}$ positiva. Sistema hifálico dimítico; hifas não amilóides e não dextrinóides; hifas generativas com septos simples, parede fina a ligeiramente espessa, 2,53,75 $\mu \mathrm{m}$ diâm.; hifas esqueléticas castanhas, com paredes espessas, 5-6,25 $\mu \mathrm{m}$ diâm. Setas presentes, subuladas a ventricosas, castanho-escuras em $\mathrm{KOH}$, parede espessa, 20-45 × 6,25-10 $\mu \mathrm{m}$. Basídios e basidiósporos não observados.

Material examinado: BRASIL. SÃo Paulo: São José do Rio Preto, Bosque Municipal, 20-XI-2005, M.C. Abrahão 29, 35, 36 (SP).

Ilustrações em Ryvarden \& Johansen (1980) e Ryvarden (2004).

Espécie de distribuição pantropical (Ryvarden 2004). Ocorre com freqüência no Brasil, citado para os Estados do Acre, Alagoas, Amapá, Amazonas, Bahia, Goiás, Mato Grosso, Pará, Paraíba, Paraná, Pernambuco, Rio Grande do Norte, Rio Grande do Sul, Rondônia, Roraima, Santa Catarina, São Paulo e Sergipe (Hennings 1900 como Polyporus gilvus (Schwein.) Fr., Fidalgo 1968a,b, Loguercio-Leite \& Wright 1991, Silveira \& Guerrero 1991, Bononi 1992, Jesus 1993, 1996, Soares \& Gugliotta 1998, Góes-Neto 1999, Góes-Neto et al. 2003, Sotão et al. 2002, 2003, Xavier-Santos 2003, Gibertoni et al. 2004, Meijer 2006 como Fuscoporia gilva (Schwein.: Fr.) T. Wagner \& M. Fischer).
Apesar da ausência de basidiósporos, a identificação da espécie foi possível através da análise das características macroscópicas (como dimensão do basidioma, coloraçãoe tamanho dos poros) e microscópicas (como dimensão das hifas himeniais, presença e formato de setas himeniais), estando de acordo com as descrições apresentadas por Ryvarden \& Johansen (1980) e Ryvarden (2004). Segundo Ryvarden \& Johansen (1980), Phellinus gilvus apresenta basidiósporos oblongos a elipsóides, hialinos a amarelo-pálidos, com parede lisa e fina, 4-5 × (2,7-) 3-3,5 (-4) $\mu \mathrm{m}$, geralmente colapsados.

Phellinus umbrinellus (Bres.) S. Herrera \& Bondartseva, Mikol. Fitopatol. 14(1): 8. 1980. इ Poria umbrinella Bres., Hedwigia 35: 282. 1896.

Basidioma perene, ressupinado, adnato, lenhoso, 3,4 $\times 1,7 \mathrm{~cm}$, até $0,6 \mathrm{~cm}$ de espessura; margem vilosa, obtusa, estéril, amarelo-dourada, até $2 \mathrm{~mm}$ larg. Superfície himenial poróide, castanho-amarelada, poros angulares, (6-) 7-8 (-9) poros por mm; tubos acinzentados, muito rasos, bem menos de $1 \mathrm{~mm}$ de profundidade. Contexto castanho, castanho-avermelhado em $\mathrm{KOH}$, até $1 \mathrm{~mm}$ de espessura. Sistema hifálico dimítico; hifas não amilóides e não dextrinóides; hifas generativas abundantes, com septo simples, hialinas a castanho-avermelhadas, não ramificadas, raramente dicotômicas, 1,5-2,5 $\mu \mathrm{m}$ diâm.; hifas esqueléticas dominantes, castanho-avermelhadas, parede espessa, 2,5-3,75 (-5,0) $\mu \mathrm{m}$ diâm. Setas ausentes. Basídios não observados. Basidiósporos subglobosos, levemente amarelados, não amilóides e não dextrinóides, parede fina e lisa, 3,75-5,0 × 2,5-3,75 $\mu \mathrm{m}$.

Material examinado: BRASIL. São PAULO: São José do Rio Preto, Mata dos Macacos, 13-XII-2005, M.C. Abrahão 63 (SP).

Ilustrações em Ryvarden \& Johansen (1980) e Gilbertson \& Ryvarden (1987).

Espécie citada para África (Ryvarden \& Johansen 1980 como Hexagonia umbrinella Fr.) e continente americano, desde os Estados Unidos da América até o Brasil (Gilbertson \& Ryvarden 1987, Ryvarden 2004). No Brasil, citada para os Estados do Alagoas, Bahia, Paraíba, Paraná, Pernambuco, Rio Grande do Norte, Santa Catarina, São Paulo e Sergipe (Loguercio-Leite \& Wright 1991, Jesus 1993, Góes-Neto 1999, Gibertoni et al. 2004, Meijer 2006 como Fomitiporella umbrinella (Bres.) Murrill).

Esta espécie pode ser caracterizada pelos poros pequenos e basidiósporos amarelados. Está relacionada a Phellinus inermis (Ellis \& Everh.) G. Cunn., que apresenta poros maiores (4-5 por $\mathrm{mm}$ ) e a espécimes ressupinados 
de Phellinus allardii (Bres.) Ryvarden, que apresentam uma ou várias zonas negras no subículo ou entre as camadas de poros, basidioma com margem irregular e mais abrupta e basidiósporos ligeiramente maiores, 4,55,5 (-6) × 4-5 $\mu \mathrm{m}$ (Ryvarden \& Johansen 1980).

\section{POLYPORALES}

\section{GANODERMATACEAE}

Ganoderma australe (Fr.) Pat., Bull. Soc. mycol. Fr. 5: 65. 1890. $\equiv$ Polyporus australis Fr., Elench. fung. (Greifswald) 1: 108. 1828.

Basidioma perene, pileado séssil, solitário. Píleo aplanado, dimidiado, semicircular a ungulado, 7,5-15 $\times$ $7,2-15,1 \mathrm{~cm}$, até $3 \mathrm{~cm}$ de espessura; margem com zonas cada vez mais claras a branca; zona estéril de até $0,7 \mathrm{~cm}$ larg. Superfície pilear opaca, concentricamente zonada, glabra, rimosa a sulcada, castanha, coberta com camada canela a castanho-clara de basidiósporos depositados. Superfície himenial poróide, branca a creme em espécimes de crescimento ativo, escurecendo quando tocada, poros circulares, 4-5 poros por $\mathrm{mm}$; tubos castanho-escuros mais claros que o contexto. Contexto castanho-escuro, com algumas inclusões brancas na parte superior, até $0,7 \mathrm{~mm}$ de espessura. Reação em KOH negativa. Sistema hifálico dimítico; hifas não amilóides e não dextrinóides; hifas generativas com ansas, hialinas, parede fina, 1,25-2,5 $\mu \mathrm{m}$ diâm.; hifas esqueléticas arboriformes abundantes no basidioma, amarelas a castanhas, parede espessa a sólida, 2,5-3,75 $\mu \mathrm{m}$ diâm., extremidade muito fina e muito ramificada, 1,25-2,5 $\mu \mathrm{m}$ diâm. Basídios não observados. Basidiósporos elipsóides, truncados, equinulados, parede dupla, parede externa hialina e fina cobrindo a interna ornamentada e castanho-dourada, não amilóides e não dextrinóides, 7,5-11,25 × 5-7,5 $\mu \mathrm{m}$.

Material examinado: BRASIL. SÃo Paulo: São José do Rio Preto, Fazenda Genética Triálogo, mata do seringal, 25-III-2006, M.C. Abrahão 95 (SP).

Ilustrações em Ryvarden \& Johansen (1980) e Ryvarden (2004).

Espécie de distribuição pantropical (Ryvarden \& Johansen 1980). No Brasil sua distribuição é incerta devido à grande dificuldade na distinção entre Ganoderma applanatum (Pers.) Pat. e G. australe; a espécie foi citada para os Estados da Bahia, Paraná, Rondônia e Santa Catarina (Capelari \& Maziero 1988, Gonçalves \& Loguercio-Leite 2001, Góes-Neto et al. 2003, Meijer 2006).

A principal característica de separação de Ganoderma applanatum e G. australe é a dimensão dos basidiósporos, além de outras características mais variáveis, como espessura da cutícula, espessura e coloração do contexto, camadas de tubos e tamanho dos poros (Gilbertson \& Ryvarden 1986, Leonard 1998). Ganoderma australe possui basidiósporos maiores, (7-) 8,0-13,0 × 5,5-8,5 $\mu \mathrm{m}$, enquanto que os basidiósporos de $G$. applanatum variam entre 4,5 e 6,0 $\mu \mathrm{m}$ diâm., raramente ultrapassam $8 \mu \mathrm{m}$ compr. (Leonard 1998). Além disso, G. australe apresenta basidioma anual com camadas de tubos contínuas, contexto mais espesso (variando entre 6 e $67 \mathrm{~mm}$ ) e com inclusões esbranquiçadas, cutícula mais espessa (a partir de $0,75 \mathrm{~mm}$ ) e 2-4 poros por mm linear (geralmente 3-4, raramente 5). Já G. applanatum apresenta basidioma anual com camadas de tubos separadas completamente por camadas de contexto de até $20 \mathrm{~mm}$, contexto variando entre 3 e $18 \mathrm{~mm}$ e com inclusões amareladas, cutícula com no máximo 0,75 $\mathrm{mm}$ de espessura e 3-6 (geralmente 4-5) poros por mm (Leonard 1998).

\section{GLOEOPHYLLACEAE}

Gloeophyllum striatum (Sw.) Murrill, Bull. Torrey bot. Club 32(7): 370. 1905. $\equiv$ Agaricus striatus Sw., Nov. Gen. Spec. Plant.: 148. 1788.

Basidioma lignícola, anual, pileado séssil, solitário a imbricado. Píleo dimidiado a flabeliforme, 0,5-5 × 0,6$3 \mathrm{~cm}, 0,1-1,3 \mathrm{~cm}$ de espessura. Superfície pilear bege a castanho-escura no início, com o tempo cinzenta à partir da base, velutina, concentricamente zonada; margem concolor à superfície pilear a pouco mais clara, inteira, lisa, aguda a obtusa, ligeiramente inflexa. Superfície himenial lamelar, castanho-escura, 1-3 lamelas por mm, finas. Contexto homogêneo, castanho-escuro, 0,1-0,5 cm de espessura. Reação em KOH positiva. Sistema hifálico dimítico; hifas não amilóides e não dextrinóides; hifas generativas com ansas, hialinas, parede fina, 2,5-3,75 $\mu \mathrm{m}$ diâm.; hifas esqueléticas castanho-amareladas, parede espessa, 3,75-6,25 $\mu \mathrm{m}$ diâm. Basídios não observados. Basidiósporos elipsóides, hialinos, não amilóides e não dextrinóides, parede fina e lisa, 8,75-10 × 3,75-5 $\mu \mathrm{m}$.

Material examinado: BRASIL. São Paulo: São José do Rio Preto, Mata da Rodovia BR153 próximo a entrada para Talhados, 3-III-2005, M.C. Abrahão 1 (SP); Bosque Municipal, 2-X-2005, M.C. Abrahão 23, 24, 25 (SP).

Ilustrações em Gilbertson \& Ryvarden (1986) e Gugliotta \& Bononi (1999).

Espécie de distribuição pantropical (Ryvarden \& Johansen 1980). No Brasil ocorre nos Estados do Amazonas, Bahia, Goiás, Mato Grosso, Minas Gerais, Pará, Paraná, Pernambuco, Rio de Janeiro, Rio Grande do 
Norte, Rio Grande do Sul, Rondônia, Santa Catarina e São Paulo (Fidalgo 1968a, Bononi et al. 1981, Loguercio-Leite \& Wright 1991, Góes-Neto 1999, Gugliotta \& Bononi 1999, Maia et al. 2002, Sotão et al. 2002, 2003, Gibertoni et al. 2004, Xavier-Santos 2003, Meijer 2006).

A coloração e o himênio lamelar são boas características para o reconhecimento da espécie no campo. Está intimamente relacionada a Gloeophyllum abietinum (Bull.:Fr.) P. Karst., espécie de distribuição temperada que difere pelo píleo alongado e basidiósporos maiores, 9-12 $\mu \mathrm{m}$ de comprimento (Gugliotta \& Bononi 1999, Núñez \& Ryvarden 2001).

\section{MERULIACEAE}

Gloeoporus thelephoroides (Hook.) G. Cunn., Bull. N.Z. Dept. Sci. Industr. Res., Pl. Dis. Div. 164:111. 1965. $\equiv$ Boletus thelephoroides Hook., Syn. P1. 1: 10. 1822.

= Gloeoporus conchoides Mont., Historia física, política y naturál de la isla de Cuba 2: 385. 1842.

Basidioma anual, pileado séssil, solitário. Píleo 4,3-7,5 × 2,6-3,4 cm, até $1 \mathrm{~cm}$ de espessura, afinado próximo à margem; margem ondulada. Superfície pilear glabra, branca, radialmente estriada nos espécimes mais velhos. Superfície himenial poróide, ocrácea, poros arredondados a angulares, 4-7 (-8) poros por $\mathrm{mm}$. Contexto branco, até $1 \mathrm{~mm}$ de espessura, separado da camada de poros por uma zona escura gelatinizada. Reação em KOH negativa. Sistema hifálico monomítico; hifas generativas não amilóides e não dextrinóides, com septo simples, hialinas, parede fina, 2,5 $\mu \mathrm{m}$ diâm. Basídios não observados. Basidiósporos cilíndricos a alantóides, hialinos, não amilóides e não dextrinóides, parede fina e lisa, 2,5-5 × 1,25 $\mu \mathrm{m}$.

Material examinado: BRASIL. São PAULo: São José do Rio Preto, Fazenda Genética Triálogo, mata do seringal, 25-III-2006, M.C. Abrahão 85 (SP).

Ilustrações em Ryvarden \& Johansen (1980) e Gilbertson \& Ryvarden (1986).

A espécie apresenta distribuição pantropical (Gilbertson \& Ryvarden 1986). No Brasil é citada para Amazonas, Bahia, Mato Grosso, Santa Catarina e São Paulo (Fidalgo 1968a como Gloeoporus conchoides, Corner 1989, Loguercio-Leite \& Wright 1991, Jesus 1993, Góes-Neto 1999, Xavier-Santos 2003).

Gloeoporus thelephoroides caracteriza-se pelo sistema hifálico monomítico, presença da camada gelatinizada separando o contexto da superfície himenial e basidiósporos alantóides, pequenos. É espécie morfologicamente semelhante a Gloeoporus dichrous (Fr.) Bres., que no entanto apresenta hifas generativas com ansas e superfície himenial avermelhada a levemente purpúrea (Gilbertson \& Ryvarden 1986).

\section{POLYPORACEAE}

Coriolopsis floccosa (Jungh.) Ryvarden, Norw. J1. Bot. 19(3-4): 230. 1972. 三 Polyporus floccosus Jungh., Praemissa in floram cryptogamicam Javae insulae (Batavia): 49. 1838.

$=$ Trametes rigida Berk. \& Mont., Annls Sci. Nat., Bot., sér. 11: 240. 1849. $\equiv$ Coriolopsis rigida (Berk. \& Mont.) Murrill, N. Amer. Fl. (New York) 9(2): 75. 1908.

Basidioma anual, efuso-reflexo a ressupinado, flexível quando fresco e rígido quando seco. Píleo hirsuto a tomentoso, escruposo e glabro em espécimes velhos, zonado concentricamente, radialmente estriado, (0,7-) 2,6-22 × (0,6-) 1,2-5,1 (-7,5) cm, 0,1-0,3 cm de espessura. Superfície pilear castanho-acinzentada, ocrácea a castanho-clara, margem concolor à superfície himenial. Superfície himenial poróide, bege a amarela ou castanha, poros circulares a angulares, freqüentemente lacerados e denteados em espécimes velhos, 2-5 poros por $\mathrm{mm}$; tubos inteiros, muitas vezes decurrentes. Contexto dúplex, castanho-claro, com a camada inferior compacta e a superior frouxa e flocosa, em alguns exemplares separadas por uma linha escura e fina. Reação em $\mathrm{KOH}$ negativa. Sistema hifálico trimítico; hifas não amilóides e não dextrinóides; hifas generativas com ansas, hialinas, parede fina, colapsadas e, portanto difíceis de encontrar, 1,25-3,75 $\mu \mathrm{m}$ diâm.; hifas esqueléticas abundantes, amarelas a douradas, parede espessa, 3,757,5 $\mu \mathrm{m}$ diâm.; hifas conectivas hialinas, parede fina, 1,25$3,75 \mu \mathrm{m}$ diâm. Basídios não observados. Basidiósporos cilíndricos, hialinos, não amilóides e não dextrinóides, parede fina e lisa, (6,25-) 7,5-8,75 (-10) × 1,25-2,5 $(-3,75) \mu \mathrm{m}$.

Material examinado: BRASIL. São PAULo: São José do Rio Preto, Bosque Municipal, 26-IX-2005, M.C. Abrahão 9, 10, 18 (SP); Bosque Municipal, 20-XI-2005, M.C. Abrahão 31, 34, 38, 40 (SP); Fazenda Genética Triálogo, mata do seringal, 9-XII-2005, M.C. Abrahão 54 (SP); Mata dos Macacos, 13-XII-2005, M.C. Abrahão 65, 66 (SP); Fazenda Genética Triálogo, mata do seringal, 25-III-2006, M.C. Abrahão, 77 (SP).

Ilustrações em Ryvarden \& Johansen (1980) e Gilbertson \& Ryvarden (1986 como Coriolopsis rigida).

Espécie de distribuição pantropical (Ryvarden \& Johansen 1980). No Brasil, citada para os Estados de Alagoas, Bahia, Pará, Paraíba, Paraná, Pernambuco, Rio 
Grande do Sul, Roraima, Santa Catarina, São Paulo e Sergipe (Rick 1963 como Trametes floccosa (Bres.) Lloyd, Bononi et al. 1981 como T. rigida, LoguercioLeite \& Wright 1991 como Coriolopsis rigida, Jesus 1996 como C. rigida, Gugliotta 1997 como C. rigida, Góes-Neto 1999, Maia et al. 2002 como C. rigida, Sotão et al. 2002, 2003 como C. rigida, Gibertoni et al. 2004 como C. rigida, Meijer 2006 como C. rigida).

Esta espécie é bastante variável e foi descrita inúmeras vezes. A superfície pilear pode ser tomentosa a híspida, sem zonas a distintamente zonada com adornos variáveis em cada zona, mas geralmente é castanhoacinzentada, ocrácea a castanho-clara. Está relacionada a Coriolopsis gallica (Fr.) Ryvarden, espécie européia com basidioma também variável, mas com poros maiores (1-2 por $\mathrm{mm}$ ) e basidioma mais espesso (1-1,5 $\mathrm{cm}$ de espessura) (Ryvarden \& Johansen 1980, Bernicchia 1990).

Coriolopsis polyzona (Pers.) Ryvarden, Norw. Jl. Bot. 19: 230. 1972. Polyporus polyzonus Pers., in Gaud., Voy. Aut. Monde: 170. 1827.

= Trametes occidentalis (Klotzsch) Fr., Epicrisis Systematis Mycologici: 491. 1838. $\equiv$ Polystictus occidentalis Klotzsch, Syll. fung. (Abellini) 6: 274. 1888. $\equiv$ Coriolopsis occidentalis (Klotzsch) Murrill, Bull. Torrey bot. Club 32(7): 358. 1905. 三 Coriolus occidentalis (Klotzsch) G. Cunn., Proc. Linn. Soc. N.S.W. 75: 233. 1950.

Basidioma anual a perene, pileado séssil, solitário a cespitoso. Píleo dimidiado, flabeliforme a reniforme, às vezes reflexo com uma base efusa, coriáceo a corticiforme, 2,0-5,0 $\times 1 \mathrm{~cm}, 0,2-0,6 \mathrm{~cm}$ de espessura. Superfície pilear velutina, concentricamente zonada e sulcada, em tons de ocráceo a castanho-claro, freqüentemente esverdeada por algas que crescem sobre os pêlos; margem tomentosa, fina, lisa a ondulada, aguda, inteira ou incisa e lobada, concolor à superfície pilear. Superfície himenial poróide, ocráceo-clara, poros angulares a circulares, 2-3 poros por $\mathrm{mm}$; tubos concolores à superfície himenial, até $3 \mathrm{~mm}$ de profundidade, simples a estratificados, dissepimentos lisos. Contexto dúplex, radialmente fibroso, ocráceo-claro, dividido por uma linha negra na parte mais velha próxima à base, cada parte até $0,3 \mathrm{~cm}$ de espessura. Reação em $\mathrm{KOH}$ negativa. Sistema hifálico trimítico; hifas não amilóides e não dextrinóides; hifas generativas com ansas, hialinas, parede fina, 3,75-5 $\mu \mathrm{m}$ diâm.; hifas esqueléticas hialinas a amareladas, parede espessa, 3,75-6,25 $\mu \mathrm{m}$ diâm.; hifas conectivas hialinas a amareladas, ramificadas, parede espessa, 1,25-3,75 ㅆm diâm. Basídios e basidiósporos não observados.

Material examinado: BRASIL. São PAULo: São José do Rio Preto, Mata da Rodovia BR153 próxima à entrada para Talhados, 5-IV-2005, M.C. Abrahão, 2 (SP); Bosque Municipal, 21-V-2005, M.C. Abrahão 5 (SP).

Ilustrações em Ryvarden \& Johansen (1980).

Espécie de distribuição pantropical (Ryvarden \& Johansen 1980). No Brasil, citada para Acre, Bahia, Mato Grosso, Paraná, Pernambuco, Santa Catarina e São Paulo (Hennings 1900 como Polystictus occidentalis, Bononi et al. 1981 como Coriolus occidentalis e Trametes occidentalis, Loguercio-Leite \& Wright 1991, Bononi 1992 como Coriolopsis occidentalis, Góes-Neto 1999 como P. occidentalis, Gerber \& Loguercio-Leite 2000, Maia et al. 2002 como Coriolopsis occidentalis, Meijer 2006).

Segundo Ryvarden \& Johansen (1980), os basidiósporos desta espécie são oblongos a ligeiramente elipsóides, hialinos, não amilóides e não dextrinóides, com parede fina e lisa, (4,5-) 5-8,5 × (2-) 2,5-3,5 $\mu \mathrm{m}$ e o tamanho varia consideravelmente dentro de uma coleção.

Esta espécie apresenta formato do basidioma bastante variável, dimidiado, flabeliforme a reniforme, às vezes reflexo com uma base efusa. Pode ser confundida com espécimes velhos de Trametes hirsuta (Wulf.:Fr.) Pilát, cujos basidiomas se tornam ocráceos a castanhoescuros após vários anos de permanência em herbário. No entanto, quando fresco, T. hirsuta apresenta superfície pilear hirsuta, acinzentada, superfície himenial tipicamente acinzentada, contexto branco e basidiósporos ligeiramente menores $(4,5-6(-7) \times(1,5-)$ 1,8-2,5 $\mu \mathrm{m})$ (Ryvarden \& Johansen 1980, Bernicchia 1990).

Datronia caperata (Berk.) Ryvarden, Mycotaxon 23: 172. 1985. $\equiv$ Polyporus caperatus Berk., Grevillea 9(51): 98. 1881 .

Basidioma lignícola, anual, pileado séssil, a efuso-reflexo, solitário ou lateralmente conato. Píleo flabeliforme, aplanado, 2,0-7,5 × 0,7-2,3 cm, 0,1-0,3 cm de espessura. Superfície pilear concentricamente zonada, zonas estreitas finamente vilosas e zonas largas tomentosas, com vários tons de castanho, levemente enrugada; margem aguda, creme a castanho-clara, inteira, glabra, zona inferior estéril de 1-3 mm larg. Superfície himenial poróide, castanho-clara a cor de canela, 3-4 poros por mm, circulares; tubos concolores à superfície himenial, até $1 \mathrm{~mm}$ de profundidade; dissepimentos agudos, inteiros. Contexto homogêneo, 
castanho-claro, até $3 \mathrm{~mm}$ de espessura na base, com linha escura entre o contexto e o tomento. Reação em KOH positiva. Sistema hifálico dimítico; hifas não amilóides e não dextrinóides; hifas generativas com ansas, parede fina, ramificadas, 1,25-2,5 $\mu \mathrm{m}$ diâm.; hifas esqueléticas predominantes, castanho-douradas, parede espessa, 3,75$5 \mu \mathrm{m}$ diâm. Medas presentes. Basídios e basidiósporos não observados.

Material examinado: BRASIL. São PaUlo: São José do Rio Preto, Bosque Municipal, 21-V-2005, $M$. C. Abrahão 3 (SP); Bosque Municipal, 26-IX-2005, M.C. Abrahão 11, 12, 13, 14 (SP); Bosque Municipal, 20-XI-2005, M.C. Abrahão 28, 32, 41 (SP).

Ilustrações em Gugliotta \& Bononi (1999).

Espécie de distribuição tropical (Gugliotta \& Bononi 1999). No Brasil, citado para os Estados do Acre, Alagoas, Bahia, Espírito Santo, Paraíba, Paraná, Pernambuco, Rio Grande do Norte, Rio Grande do Sul, Rondônia, Santa Catarina, São Paulo e Sergipe (Rick 1963 como Trametes caperata (Berk.) Teixeira, Bononi et al. 1981 como T. caperata, Capelari \& Maziero 1988, Vinha 1988 como T. caperata, Bononi 1992, Gugliotta 1997, Góes-Neto 1999, 2003, Gugliotta \& Bononi 1999, Gerber \& Loguercio-Leite 2000, Maia et al. 2002 como Coriolus caperatus (Berk.) Pat., Gibertoni \& Cavalcanti 2003, Gibertoni et al. 2004, Meijer 2006).

Segundo Gugliotta \& Bononi (1999), os basidiósporos desta espécie são cilíndricos, hialinos, não amilóides e não dextrinóides, parede fina e lisa, $8,4-9,6 \times 2,4 \mu \mathrm{m}$.

A superfície pilear pode variar quanto à textura e cor, mas a presença de zonas concêntricas estreitas finamente vilosas e zonas largas tomentosas são boas características para o reconhecimento da espécie, além da presença de poros geralmente pequenos e contexto castanho (Ryvarden \& Johansen, 1980). Devido à grande variação morfológica, principalmente na superfície pilear, esta espécie já foi descrita várias vezes, apresentando inúmeros sinônimos (Index Fungorum, CABI Bioscience et al. 2008).

Datronia mollis (Sommerf.) Donk., Persoonia 4(3): 338. 1967. [1966] $\equiv$ Daedalea mollis Sommerf., Suppl. F1. appl. (Oslo) 271. 1826.

Basidioma anual, ressupinado a efuso-reflexo, 2-6 (-14,5) × 0,4-1,2 (-7) cm, 0,1-0,3 cm de espessura, facilmente destacável do substrato, flexível quando fresco, tornando-se mais rígido ao secar. Superfície pilear, quando presente, finamente tomentosa, zonada e sulcada, castanho-escura próximo à base e castanho- clara próximo à margem; margem definida, zona estéril até $2 \mathrm{~mm}$ larg., concolor à superfície himenial. Superfície himenial castanho-clara; poros circulares a angulares, freqüentemente lacerados, dedalóides, quase lamelados, 1-2 poros por $\mathrm{mm}$; tubos com até $2 \mathrm{~mm}$ de profundidade. Contexto homogêneo, compacto, de cor bege, até $1 \mathrm{~mm}$ de espessura, separado do tomento por fina linha preta. Reação em KOH negativa. Sistema hifálico trimítico; hifas não amilóides e não dextrinóides; hifas generativas com septo simples, hialinas, parede fina, difíceis de visualizar, 2,5-3,75 $\mu \mathrm{m}$ diâm.; hifas esqueléticas abundantes, amareladas, parede espessa, 2,5-3,75 $\mu \mathrm{m}$ diâm.; hifas conectivas amarelas, parede espessa, muito ramificadas, 2,5-3,75 $\mu$ m diâm. Basídios não observados. Basidiósporos cilíndricos, hialinos, não amilóides e não dextrinóides, parede fina e lisa, 7,5-10 $\times$ 2,5-3,75 (-5) $\mu \mathrm{m}$.

Material examinado: BRASIL. São Paulo: São José do Rio Preto, Bosque Municipal, 26-IX-2005, M.C. Abrahão 17 (SP).

Ilustrações em Gilbertson \& Ryvarden (1986) e Silveira \& Guerrero (1991).

Espécie de distribuição cosmopolita (Nuñez \& Ryvarden 2001). No Brasil, citada para os Estados do Acre, Paraná e Rio Grande do Sul (Rick 1963 como Trametes mollis (Sommerf.) Fr., Silveira \& Guerrero 1991, Bononi 1992, Meijer 2006). Tratase da primeira referência da espécie para o Estado de São Paulo.

Gilbertson \& Ryvarden (1986) descrevem para a espécie basidiósporos de 10-12 × 3-4,5 $\mu \mathrm{m}$, maiores que os observados no presente estudo. No entanto, os basidiósporos do material examinado estão de acordo com as observações de Silveira \& Guerrero (1991) e Corner (1989), assim como o sistema hifálico, considerado trimítico.

Hexagonia hirta (P. Beauv.) Fr., Epicr. Syst. Mycol. (Upsaliae): 496. 1838. 三Favolus hirtus P. Beauv., Flore Oware Benin 1: 74. 1805.

Basidioma anual, solitário a imbricado, sempre pileado séssil, fixo ao substrato por uma pequena porção pilear; píleo dimidiado, flabeliforme, convexo a aplanado, coriáceo, 3,5-10 (-15,5) × 2,5-6 (-9) cm, (0,2-) 0,3-1,2 (-3) cm de espessura. Superfície pilear castanho-escura a quase preta, fibrilosa, densamente coberta por pêlos rígidos, fasciculados e pretos, caindo parcial ou completamente com a idade, deixando às vezes superfície zonada com algumas fibrilas aglutinadas. Superfície himenial castanho-amarelada a acinzentada ou 
castanho-escura, sempre poróide, muito raramente com poros lacerados e irpicóides, mas nunca dedalóide ou lamelada, poros angulares, isodiamétricos a alongados, extremamente variáveis em tamanho, 8-16 poros por $\mathrm{cm}$. Contexto coriáceo, permanentemente escurecido em solução de $\mathrm{KOH}$, sub-homogêneo, castanhoferrugíneo, algumas vezes castanho-claro próximo à margem de crescimento, geralmente castanho-escuro no ponto de inserção. Sistema hifálico trimítico; hifas não amilóides e não dextrinóides; hifas generativas com ansas, hialinas, parede fina, 1,25-2,5 (-3,75) $\mu \mathrm{m}$ diâm.; hifas esqueléticas castanho-amareladas, parede espessa, com lúmen distinto, (3,75-) 5-7,5 $\mu \mathrm{m}$ diâm.; hifas conectivas hialinas a castanho-amareladas, (1-) 1,5-2,5 (-5) $\mu \mathrm{m}$ diâm. Basídios não observados. Basidiósporos cilíndricos, hialinos, não amilóides e não dextrinóides, parede fina e lisa, 8,75-13,75 $(-16,25) \times$ 3,75-5 (-6,25) $\mu \mathrm{m}$.

Material examinado: BRASIL. São PAulo: São José do Rio Preto, Fazenda Genética Triálogo, mata do seringal, 25-III-2006, M.C. Abrahão 71, 76, 78, 82, 84, $86,87,88,90,93$ (SP).

Ilustrações em Fidalgo (1968b) e Ryvarden \& Johansen (1980).

A espécie era considerada até recentemente como restrita geograficamente à África (Fidalgo 1968b, Ryvarden \& Johansen 1980), mas foi encontrada na América Tropical, no México (Mora \& Garza 1997). No Brasil foi citada para o Estado de São Paulo (XavierSantos 2003).

Hexagonia hirta é macroscopicamente semelhante a H. apiaria (Pers.) Fr., que apresenta poros maiores, (1-) 2-4 (-8) poros por $\mathrm{cm}$, hifas cistidiformes formadas por terminações de hifas esqueléticas presentes no himênio, medas abundantes e basidiósporos levemente maiores, 11-15 (-16) × 4,5-6 $\mu \mathrm{m}$. H. cappilacea Pat. é outra espécie que também ocorre no Brasil e pode ser confundida com $H$. hirta, da qual se distingue facilmente pela presença de hifas setiformes no himênio, fusiformes a ventricosas, castanhas, de parede espessa, às vezes ramificadas, algumas com depósitos no ápice, denominadas pseudosetas (Fidalgo 1968b).

Hexagonia hydnoides (Sw.) M. Fidalgo, Mem. N. Y. bot. Gdn. 17: 64. 1968. इ Boletus hydnoides Sw., Fl. Ind. Occid. 3: 1942. 1806.

Basidioma lignícola, sempre pileado séssil, solitário a imbricado, anual, ligado ao substrato por uma pequena porção do píleo mais alargada. Píleo flabeliforme a ungulado, aplanado, 6,5-14,6 × 3,4-7,1 cm, 0,2-1 cm de espessura. Superfície pilear fimbriada, com pêlos ramificados de aproximadamente $0,5 \mathrm{~cm}$ de comprimento, glabra na maturidade, castanho-escura, concentricamente zonada; margem inteira a levemente lobada, concolor à superfície pilear, glabra, aguda, direita, zona inferior estéril menor que $0,1 \mathrm{~cm}$ larg., às vezes ausente. Superfície himenial poróide, castanha mais clara que a superfície pilear, 3-5 poros por mm, regulares, circulares; tubos concolores à superfície himenial. Contexto homogêneo, cor de canela a castanho-escuro, 0,1-0,2 cm de espessura. Reação em KOH positiva. Sistema hifálico trimítico; hifas não amilóides e não dextrinóides; hifas generativas de difícil visualização, com ansas, hialinas, parede fina, 2,5-3,75 $\mu \mathrm{m}$ diâm.; hifas esqueléticas castanho-oliváceas, parede espessa, 3,75-6,25 $\mu \mathrm{m}$ diâm.; hifas conectivas hialinas a castanho-amareladas, muito tortuosas e ramificadas, parede espessa, 1,25-3,75 $\mu$ m diâm. Basídios não observados. Basidiósporos cilíndricos, hialinos, não amilóides e não dextrinóides, parede fina e lisa, 8,75$11,25 \times 2,5-3,75 \mu \mathrm{m}$.

Material examinado: BRASIL. São PAUlo: São José do Rio Preto, Bosque Municipal, 21-V-2005, M.C. Abrahão 4 (SP); Bosque Municipal, 10-X-2005, M.C. Abrahão 26 (SP).

Ilustrações em Fidalgo (1968b), Gilbertson \& Ryvarden (1986) e Gugliotta \& Bononi (1999).

Espécie de distribuição pantropical (Gilbertson \& Ryvarden 1986). Segundo Gugliotta \& Bononi (1999), a espécie é comum em florestas úmidas no Brasil e principalmente em áreas mais secas, como os cerrados e cerradões. No Brasil, está citada para os Estados de Alagoas, Amazonas, Bahia, Espírito Santo, Goiás, Maranhão, Mato Grosso, Pará, Paraná, Pernambuco, Rio de Janeiro, Rio Grande do Norte, Rio Grande do Sul, Rondônia, Roraima, Santa Catarina, São Paulo e Sergipe (Rick 1963 como Trametes hydnoides (Sw.) Fr., Fidalgo 1968a,b, Bononi et al. 1981, Capelari \& Maziero 1988, Vinha 1988 como Pogonomyces hydnoides (Sw.) Murrill, Loguercio-Leite \& Wright 1991, Jesus 1996, Gugliotta 1997, Góes-Neto 1999, Gugliotta \& Bononi 1999, Gonçalves \& Loguercio-Leite 2001, Maia et al. 2002, Sotão et al. 2002, 2003, Góes-Neto et al. 2003, Gibertoni \& Cavalcanti 2003, Gibertoni et al. 2004, Xavier-Santos 2003, Meijer 2006).

Hexagonia hydnoides pode ser facilmente reconhecível pela densa massa de pêlos eretos e escuros na superfície pilear, geralmente em zonas distintas, pela forma e tamanho dos poros, cor do contexto e tamanho dos basidiósporos. A espécie mais próxima de $H$. hydnoides é $H$. hirta, da qual se separa por possuir poros menores e menos variáveis (3-5 poros por $\mathrm{mm}$ ), além 
de basidiósporos menores (8,75-11,25 × 2,5-3,75 $\mu \mathrm{m})$, enquanto que $H$. hirta possui poros de $8-16$ poros por $\mathrm{cm}$ e basidiósporos 8,75-13,75 $(-16,25) \times 3,75-5(-6,25) \mu \mathrm{m}$ (Fidalgo 1968b).

Hexagonia hydnoides aparentemente pode se tornar parasita, uma vez que já foi observada em abundância em troncos mortos ou ramos secos de árvores vivas, porém nunca em partes vivas (Fidalgo 1968b, Gilbertson \& Ryvarden 1986, Gugliotta \& Bononi 1999). No Bosque Municipal este fato foi observado, e um espécime (M.C. Abrahão 4) foi encontrado em galho podre de uma árvore viva, porém não é possível afirmar que a espécie seja parasita, já que o galho pode ter sido colonizado após a sua morte.

Hexagonia papyracea Berk., Ann. Mag. Nat. Hist. sér. 1. 10: 379. 1843.

= Hexagona variegata Berk., Ann. Mag. Nat. Hist. sér. 2. 9: 196. 1852.

Basidioma lignícola, anual, pileado séssil a efusoreflexo, solitário a lateralmente conato. Píleo dimidiado a flabeliforme, (1-) 1,4-8,3 × 1-5,7 cm, 0,1-0,2 (-0,4) cm de espessura. Superfície pilear concentricamente zonada, zonas purpúreas e castanhas, claras e escuras, castanho-escura e velutina próxima ao ponto de inserção tornando-se glabra e castanho-escura com a maturidade; margem acinzentada a castanho-clara, direita, lobada a ondulada, aguda, zona inferior estéril de 0,1-0,2 cm larg. Superfície himenial poróide, de cor muito variável de acordo com o tempo de maturidade (cinza pálido, castanho-clara a cor de fuligem), 1,5-3 poros por mm, regulares, hexagonais. Contexto homogêneo, castanhoescuro, aproximadamente $0,1 \mathrm{~cm}$ de espessura. Reação em KOH positiva. Sistema hifálico trimítico; hifas não amilóides e não dextrinóides; hifas generativas de difícil visualização, com ansas, hialinas, parede fina, 1,253,75 $\mu \mathrm{m}$ diâm.; hifas esqueléticas amarelo-acastanhadas, parede espessa, 2,5-5 $\mu \mathrm{m}$ diâm.; hifas conectivas hialinas a levemente amareladas, ramificadas, parede espessa, 2,5$3,75 \mu \mathrm{m}$ diâm. Basídios não observados. Basidiósporos cilíndricos, hialinos, não amilóides e não dextrinóides, parede fina e lisa, 8,75-12,5 × 3,75-5 $\mu \mathrm{m}$.

Material examinado: BRASIL. São PaUlo: São José do Rio Preto, Bosque Municipal, 20-XI-2005, M.C. Abrahão 30, 37, 39 (SP); Mata dos Macacos, 06-II-2006, M.C. Abrahão 67 (SP); Fazenda Genética Triálogo, mata do seringal, 25-III-2006, M.C. Abrahão 72, 73, 79, 80, 83, 94 (SP).

Ilustrações em Fidalgo (1968b) e Gugliotta \& Bononi (1999).
Espécie de distribuição pantropical (Gugliotta \& Bononi 1999). No Brasil, citada para os Estados do Alagoas, Amapá, Amazonas, Bahia, Espírito Santo, Goiás, Maranhão, Mato Grosso, Minas Gerais, Pará, Paraíba, Paraná, Pernambuco, Rio de Janeiro, Rio Grande do Norte, Rio Grande do Sul, Roraima, Santa Catarina, São Paulo e Sergipe (Fidalgo 1968b, Vinha 1988 como Hexagona variegata, Loguercio-Leite \& Wright 1991, Jesus 1996, Gugliotta 1997, Góes-Neto 1999, Gugliotta \& Bononi 1999, Maia et al. 2002, Sotão et al. 2003, XavierSantos 2003, Gibertoni et al. 2004, Meijer 2006).

Hexagonia papyracea é facilmente reconhecível devido ao basidioma fino, flexível, castanho, fortemente zonado, com poros grandes (Gugliotta \& Bononi 1999).

H. variegata Berk. é considerado nome corrente para a espécie nas bases de dados do Fungal Biodiversity Centre e do Index Fungorum (CABI Bioscience et al. 2008, CBS 2008). No entanto, a publicação de $H$. papyracea realizada por Berkeley em 1843 foi anterior à validação de $H$. variegata, que só ocorreu em 1852. A questão nomenclatural da espécie foi detalhadamente descrita por Fidalgo (1968b).

Polyporus tenuiculus (P. Beauv.) Fr., Syst. mycol. (Lundae) 1: 344. 1821. EFavolus tenuiculus P. Beauv. Fl. Oware 1: 74. 1806.

= Polyporus dermoporus Pers., Voy. Uranie. Bot. 5. 1827.

= Favolus brasiliensis (Fr.) Fr., Linnaea 5: 511. 1830.

Basidioma lignícola, anual, pileado estipitado, solitário ou em pequenos grupos, lateralmente conato. Píleo flabeliforme, espatulado a dimidiado e semicircular, 0,5-5 (-7) × 0,3-3 (-5,3) cm, 0,2-0,3 (-0,4) cm de espessura. Superfície pilear ocrácea, castanho-clara ou creme, glabra, tesselada; margem concolor à superfície pilear, às vezes pouco mais escura, glabra, direita, involuta quando seca, inteira a ligeiramente lobada. Estipe lateral a central, cilíndrico, concolor à superfície pilear, curto, $0,5-1,3 \times 0,2-0,5 \mathrm{~cm}$. Superfície himenial poróide, concolor à superfície pilear, 1-3 poros por $\mathrm{mm}$, hexagonais a radialmente alongados. Contexto homogêneo, branco a creme-claro, 0,1-0,2 cm de espessura. Reação em $\mathrm{KOH}$ negativa. Sistema hifálico dimítico; hifas não amilóides e não dextrinóides; hifas generativas de difícil visualização, ansas não observadas, hialinas, parede fina e lisa, 1,25-3,75 $\mu \mathrm{m}$ diâm.; hifas conectivas hialinas, arboriformes, parede espessa, às vezes lembrando hifa esquelética, 2,5-6,25 $\mu \mathrm{m}$ diâm. Basídios e basidiósporos não observados. 
Material examinado: BRASIL. São PAulo: São José do Rio Preto, Fazenda Genética Triálogo, mata do seringal, 09-XII-2005, M.C. Abrahão 42, 43, 44, 45, $46,47,50$ (SP).

Ilustrações em Gilbertson \& Ryvarden (1987), Silveira \& Wright (2005) e Louza \& Gugliotta (2007).

Espécie de distribuição pantropical (Louza \& Gugliotta 2007). No Brasil, ocorre em Alagoas, Bahia, Mato Grosso, Pará, Paraíba, Paraná, Pernambuco, Rio de Janeiro, Rio Grande do Norte, Rio Grande do Sul, Rondônia, Roraima, Santa Catarina, São Paulo e Sergipe (Singer 1961 como Polyporus dermoporus, Rick 1963 como Favolus brasiliensis, Prance 1973, Capelari \& Maziero 1988 como F. brasiliensis, Loguercio-Leite \& Wright 1991 como F. brasiliensis, Gugliotta 1997, Sotão et al. 1997, Góes-Neto 1999, Gugliotta \& Bononi 1999, Gonçalves \& Loguercio-Leite 2001 como F. brasiliensis, Maia et al. 2002, Gibertoni \& Cavalcanti 2003, GóesNeto et al. 2003, Xavier-Santos 2003, Gibertoni et al. 2004, Silveira \& Wright 2005, Meijer 2006 como F. brasiliensis, Louza \& Gugliotta 2007).

Segundo Louza \& Gugliotta (2007) os basidiósporos são cilíndricos a subcilíndricos, hialinos, não amilóides e não dextrinóides, parede fina e lisa, 6,25-10 (-11) × 2,5-5 $\mu \mathrm{m}$.

Polyporus tenuiculus é uma espécie comum e de fácil reconhecimento devido ao basidioma branco a creme quando fresco, com a superfície pilear distintamente tesselada e superfície himenial com grandes poros hexagonais a radialmente alongados (Silveira \& Wright 2005, Louza \& Gugliotta 2007).

Pycnoporus sanguineus (L.) Murrill, Bull. Torrey bot. Club 31(8): 421. 1904. 三Boletus sanguineus L., Sp. pl., Edn. 2: 1646. 1763.

Basidioma lignícola, anual, pileado séssil a subestipitado, solitário a lateralmente conato. Píleo dimidiado a flabeliforme, 1,7-9,5 × 1,1-5,1 (-6,5) cm $(0,1-) \quad 0,2-0,5 \mathrm{~cm}$ de espessura. Superfície pilear vermelho-alaranjada, puberulosa, esbranquiçada e glabra na maturidade, concentricamente zonada; margem concolor à superfície pilear, glabra, aguda, inteira, zona inferior estéril menor que $0,1 \mathrm{~cm}$ larg. Superfície himenial poróide, concolor, 2-8 poros por $\mathrm{mm}$, regulares, angulares. Contexto homogêneo, branco, com bandas concêntricas avermelhadas, até $0,1 \mathrm{~cm}$ de espessura. Reação em KOH negativa. Sistema hifálico trimítico; hifas não amilóides e não dextrinóides; hifas generativas com ansas, hialinas, parede fina, 1,25-2,5 $\mu \mathrm{m}$ diâm.; hifas esqueléticas hialinas, parede espessa, 3,75-6,25 $\mu \mathrm{m}$ diâm.; hifas conectivas hialinas, ramificadas, parede espessa, 1,25-2,5 $\mu \mathrm{m}$ diâm. Basídios não observados. Basidiósporos levemente cilíndricos, hialinos, não amilóides e não dextrinóides, parede fina e lisa, 5-6,25 $\times 1,25-2,5 \mu \mathrm{m}$.

Material examinado: BRASIL. São Paulo: São José do Rio Preto, Bosque Municipal, 2-X-2005, M.C. Abrahão 20, 21, 22 (SP); Fazenda Genética Triálogo, mata do seringal, 9-XII-2005, M.C. Abrahão 55 (SP); Mata dos Macacos, 13-XII-2005, M.C. Abrahão 60, 61 (SP).

Ilustrações em Ryvarden \& Johansen (1980), Gilbertson \& Ryvarden (1987) e Gugliotta \& Bononi (1999).

Espécie de distribuição pantropical (Gugliotta \& Bononi 1999). No Brasil, citada para Alagoas, Amapá, Bahia, Espírito Santo, Mato Grosso, Pará, Paraíba, Paraná, Pernambuco, Rio de Janeiro, Rio Grande do Norte, Rio Grande do Sul, Rondônia, Santa Catarina e São Paulo (Hennings 1900 como Polystictus sanguineus (L.) G. Mey., Rick 1963, Fidalgo 1970, Bononi et al. 1981, Capelari \& Maziero 1988, Vinha 1988, LoguercioLeite \& Wright 1991, Silveira \& Guerrero 1991, GóesNeto 1999, 2003, Gugliotta \& Bononi 1999, Gonçalves \& Loguercio-Leite 2001, Sotão et al. 2002, 2003, XavierSantos 2003, Gibertoni et al. 2004, Meijer 2006).

Pycnoporus sanguineus é encontrado em troncos caídos ou não de quase todos os tipos de madeira decídua, especialmente comum em locais abertos e ensolarados, sendo facilmente reconhecível pelo basidioma vermelhoalaranjado (Jesus 1993).

Trametes modesta (Kunze:Fr.) Ryvarden, Norw. J. Bot. 19: 236. 1972. $\equiv$ Polyporus modestus Kunze:Fr., Linnaea 5: 519. 1830.

Basidioma anual, pileado séssil. Píleo aplanado, solitário; píleo único semicircular a flabeliforme com base contraída, $1,5 \times 1,8 \mathrm{~cm}, 0,4 \mathrm{~cm}$ de espessura, flexível quando fresco e seco; variável com a idade e desenvolvimento, finamente velutino e com zonas concêntricas em tons de castanho claro; sem cutícula no píleo. Superfície himenial poróide, poros circulares, pequenos, 6-10 poros por mm e quase invisíveis a olho nu, tubos bege, até $2 \mathrm{~mm}$ de profundidade. Contexto branco a bege ou castanho-claro, fácil de cortar em seções finas, fibroso, tornando-se vermelho-canela durante alguns minutos em solução de KOH. Sistema hifálico trimítico; hifas não amilóides e não dextrinóides; hifas generativas com ansas, hialinas, parede fina, 1,25-3,75 $\mu \mathrm{m}$ diâm.; hifas esqueléticas dominantes no basidioma, castanho- 
claras a amareladas, usualmente com lúmen distinto, 3,75-5 $\mu \mathrm{m}$ diâm.; hifas conectivas escassas no contexto, pouco ramificadas, parede espessa a sólida, 1,25-2,5 $\mu \mathrm{m}$ diâm. Basídios e basidiósporos não observados.

Material examinado: BRASIL. São PAULo: São José do Rio Preto, Bosque Municipal, 26-IX-2005, M.C. Abrahão 8 (SP).

Ilustrações em Ryvarden \& Johansen (1980) e Gilbertson \& Ryvarden (1987).

Espécie de distribuição pantropical (Ryvarden \& Johansen 1980, Corner 1989). No Brasil citada para os Estados do Acre, Bahia, Pernambuco, Rondônia, Roraima e São Paulo (Torrend 1924 como Polyporus modestus Fr., Capelari \& Maziero 1988, Bononi 1992, Jesus 1996, Góes-Neto 1999, Gibertoni \& Cavalcanti 2003).

Segundo Ryvarden \& Johansen (1980) os basidiósporos são cilíndricos, 4,5-6 × 1,5-2,0 (-2,5) $\mu \mathrm{m}$, parede fina e lisa, hialinos, não amilóides e não dextrinóides.

Trametes modesta pode ser confundido com $T$. menziesii (Berk.) Ryvarden, que algumas vezes pode apresentar basidioma ocráceo a esbranquiçado, no entanto pode ser facilmente reconhecido devido ao contexto vermelho-canela em $\mathrm{KOH}$ e às hifas conectivas pouco ramificadas e raras (Ryvarden \& Johansen 1980).

Agradecimentos - À Fapesp, pela bolsa de iniciação científica de M.C. Abrahão (processo 05/55136-8) e à Aline Z. L. Gonçalves e Natália Martin pela colaboração nos trabalhos de campo.

\section{Referências bibliográficas}

BERNICCHIA, A.R. 1990. Polyporaceae s.l. in Italia. Istituto di Patologia Vegetale, Bologna.

BONONI, V.L.R. 1992. Fungos macroscópicos de Rio Branco, Acre, Brasil. Hoehnea 19:31-37.

BONONI, V.L.R., TRUFEM, S.F.B. \& GRANDI, R.A.P. 1981. Fungos macroscópicos do Parque Estadual das Fontes do Ipiranga, São Paulo, Brasil, depositados no herbário do Instituto de Botânica. Rickia 9:37-53.

CABI Bioscience, CBS \& Landcare Research. 2008. Index Fungorum. http://www.indexfugorum.org (acesso em 18/01/2008).

CAPELARI, M. \& MAZIERO, R. 1988. Fungos macroscópicos do Estado de Rondônia região dos Rios Jaru e Ji-Paraná. Hoehnea 15:28-36.

CBS. 2008. Fungal Biodiversity Centre. http://www.cbs. knaw.nl/databases/ (acesso em 19/01/2008).

COOKE, W.M. 1961. The genus Schizophyllum. Mycologia 53:575-599.

CORNER, E.J.H. 1989. Ad Polyporaceas V. Beihefte zur Nova Hedwigia 96. J. Cramer, Berlin.
FIDALGO, M.E.P.K. 1968a. Contribution to the fungi of Mato Grosso, Brasil. Rickia 3:171-219.

FIDALGO, M.E.P.K. 1968b. The genus Hexagona. Memoirs of the New York Botanical Garden 17:35-108.

FIDALGO, O. 1970. Adições à história da micologia brasileira. I. A coleta mais antiga. Rickia 5:1-3.

FIDALGO, O. \& BONONI, V.L.R. (coords.). 1984. Técnicas de coleta, preservação e herborização de material

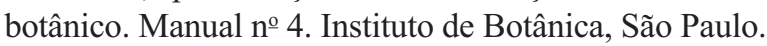

FIDALGO, O. \& FIDALGO, M.E.P.K. 1967. Dicionário micológico. Rickia Suplemento 2. Instituto de Botânica, São Paulo.

GERBER,A.L. \& LOGUERCIO-LEITE, C. 2000. Polyporoid wood-rotting fungi (Basidiomycetes). II - New records from Southern Brazil. Mycotaxon 76:175-185.

GIBERTONI, T.B. \& CAVALCANTI, M.A.Q. 2003. A mycological survey of the Aphyllophorales (Basidiomycotina) of the Atlantic Rain Forest in the State of Pernambuco, Brazil. Mycotaxon 87:203-211.

GIBERTONI, T.B., RYVARDEN, L. \& CAVALCANTI, M.A.Q. 2004. Poroid fungi (Basidiomycota) of the Atlantic Rain Forest in Northeast Brazil. Synopsis Fungorum 18:33-43.

GILBERTSON, R.L. \& RYVARDEN, L. 1986. North American Polypores. Fungiflora, Oslo, v.1.

GILBERTSON, R.L. \& RYVARDEN, L. 1987. North American Polypores. Fungiflora, Oslo, v.2.

GÓES-NETO,A. 1999. Polypore diversity in the State of Bahia, Brazil: a historical review. Mycotaxon 72:43-56.

GÓES-NETO, A., MARQUES, M.F.O., ANDRADE, J.D. \& SANTOS, D.S. 2003. Lignicolous Aphyllophoroid Basidiomycota in an Atlantic Forest fragment in the semi-arid Caatinga region of Brazil. Mycotaxon 88:359-364.

GONÇALVES, G.V.C. \& LOGUERCIO-LEITE, C. 2001. Biodiversidade de fungos poróides xilófilos (Basidiomycetes), na Unidade de Conservação Ambiental Desterro (UCAD), Ilha de Santa Catarina, SC, Brasil. Insula 30:1-19.

GROPOSO,C.\&LOGUERCIO-LEITE,C.2005.Contribution to the lignocellulolytic fungi (Basidiomycetes) of the Atlantic Rain Forest in Southern Brazil. Mycotaxon 92:103-106.

GUGLIOTTA, A.M. 1997. Polyporaceae de mata ciliar da Estação Experimental e Reserva Biológica de MojiGuaçu, São Paulo, Brasil. Hoehnea 24:89-106.

GUGLIOTTA, A.M. \& BONONI, V.L.R. 1999. Polyporaceae do Parque Estadual da Ilha do Cardoso, SP, Brasil. Boletim do Instituto de Botânica 12:1-112.

HENNINGS, V.P. 1900. Fungi mattogrossenses a Dr. R. Pilger collecti 1899. Hedwigia 39:134-139.

HIBBETT, D.S. \& THORN, R.G. 2001. Basidiomycota: Homobasidiomycetes. In The mycota VII Part B: systematic and evolution (K. Esser \& P.A. Lemke, eds.). Springer-Verlag, Berlin, p.121-168. 
JESUS, M.A. 1993. Basidiomicetos lignocelulolíticos de floresta nativa e de Pinus elliottii Engelm. do Parque Estadual das Fontes do Ipiranga, São Paulo, SP. Hoehnea 20:119-126.

JESUS, M.A. 1996. Contribution to the knowledge of woodrotting fungi in Brazil. II. Check-list of fungi from Maracá Island, Roraima State. Mycotaxon 57:323-328.

KIRK, P.M., CANNON, P.F., DAVID, J.C. \& STALPERS, J.A. 2001. Ainsworth \& Bisby's Dictionary of the fungi. $9^{\text {th }}$ ed., CABI Publishing, Wallingford.

LEONARD, A.C. 1998. Two Ganoderma species compared. Mycologist 12:65-68.

LINDER, D.H. 1933. The genus Schizophyllum. I. Species of the Western Hemisphere. American Journal of Botany 20:552-564.

LOGUERCIO-LEITE, C.\&WRIGHT, J.E. 1991. Contribution to a biogeographical study of the Austro-American xylophilous polypores (Aphyllophorales) from Santa Catarina Island, SC, Brazil. Mycotaxon 41:161-166.

LOUZA, G.S.G. \& GUGLIOTTA, A.M. 2007. Polyporus Fr. (Polyporaceae) no Parque Estadual das Fontes do Ipiranga, São Paulo, SP, Brasil. Hoehnea 34:367-384.

MAIA, C.L., YANO-MELO, A.M. \& CAVALCANTI, M.A. 2002. Diversidade de fungos no Estado de Pernambuco. In Diagnóstico da biodiversidade de Pernambuco - Recife (M. Tabarelli \& J.M.C. Silva, orgs.). Editora Massangana, Recife, v.1, p.15-50.

MEIJER, A.A.R. 2006. Preliminary list of the Macromycetes from the Brazilian State of Paraná. Boletim do Museu Botânico Municipal, Curitiba 68:04-55.

MORA, R.N. \& GARZA, R.V. 1997. Los macromicetos de la Sierra de Nanchititla, I. Polibotánica 5:21-36.

NUÑEZ, M. \& RYVARDEN, L. 2001. East Asian Polypores. Polyporaceae s. lato. Fungiflora, Oslo, v.2.

PEGLER, D.N. 1983. Agaric flora of Lesser Antilles. Kew Bulletin Additional Series 9:1-668.

PRANCE, G.T. 1973. Phytogeographic support for the theory of Pleistocene forest refuges in the Amazon Basin, based on evidence from distribution patterns in Caryocaraceae, Chrysobalanaceae, Dichapetalaceae and Lecythidaceae. Acta Amazônica 3:5-29.

RAYNER, A.D.M. 1995. Fungi, a vital component of ecosystem function in woodland. In Microbial diversity and ecosystem function (D. Allsopp, R.R. Colwell \& D.L. Hawksworth, eds.). University Press, Cambridge, p.231-251.

RICK, S.J.J. 1963. Basidiomycetes Eubasidii in Rio Grande do Sul, Brasília - Index. Séries Científicas do Museu Rio-Grandense de Ciências Naturais, Porto Alegre, RS, Brasil. Série Botânica 11:1-32.
RYVARDEN, L. 1991. Genera of Polypores. Nomenclature and taxonomy. Synopsis Fungorum 5:1-363.

RYVARDEN, L. 2004. Neotropical Polypores, Hymenochaetaceae and Ganodermataceae. Synopsis Fungorum 19:1-227.

RYVARDEN, L. \& JOHANSEN, I. 1980. A preliminary polypore flora of East Africa. Fungiflora, Oslo.

SILVEIRA, R.M.B. \& GUERRERO, R.T. 1991. Aphyllophorales poliporóides (Basidiomycetes) do Parque Nacional de Aparados da Serra, Rio Grande do Sul. Boletim do Instituto de Biociências da Universidade Federal do Rio Grande do Sul 48:1-27.

SILVEIRA, R.M.B. \& WRIGHT, J.E. 2005. The taxonomy of Echinochaete and Polyporus s. str. in Southern South America. Mycotaxon 93:1-59.

SINGER, R. 1961. Fungi of Northern Brazil. Publicações do Instituto de Micologia da Universidade do Recife 304:1-26.

SOARES, S.C.S. \& GUGLIOTTA, A.M. 1998. Criptógamos do Parque Estadual das Fontes do Ipiranga, São Paulo, SP. Fungos, 7: Aphyllophorales (Hymenochaetaceae). Hoehnea 25:11-31.

SOTÃO, H.M.P., HENNEN, J.F., GUGLIOTTA, A.M., MELO, O.A. \& CAMPOS, E.L. 1997. Fungos Basidiomycotina. In Caxiuanã (P. Lisboa, org.). Museu Paraense Emílio Goeldi, Belém, p.213-219.

SOTÃO, H.M.P., CAMPOS, E.L., COSTA, S.P.S.E., MELO, O.A. \& AZEVEDO, J.C. 2002. Basidiomycetes macroscópicos de manguezais de Bragança, Pará, Brasil. Hoehnea 29:215-224.

SOTÃO, H.M.P., CAMPOS, E.L., GUGLIOTTA, A.M. \& COSTA, S.P.S.E. 2003. Fungos macroscópicos: Basidiomycetes. In Os manguezais da costa norte brasileira (M.E.B. Fernandes, org.). Fundação Rio Bacanga, São Luis, p.45-59.

TEIXEIRA, A.R. 1995. Método para estudo das hifas do basidiocarpo de fungos poliporáceos. Manual no 6 . Instituto de Botânica, São Paulo.

TORREND, C. 1924. Les polyporacées du Brésil. Brotéria, série. Botânica 21:12-42.

VINHA, P.C. 1988. Fungos macroscópicos do Estado do Espírito Santo depositados no Herbário Central da Universidade Federal do Espírito Santo, Brasil. Hoehnea 15:57-64.

XAVIER-SANTOS, S. 2003. Isolamento, identificação e perfil enzimático de fungos decompositores de madeira da Estação Ecológica do Noroeste Paulista - São José do Rio Preto/Mirassol, SP. Tese de doutorado, Universidade Estadual Paulista, Rio Claro. 